BMJ Open Diabetes Research \& Care

\title{
Corresponding waist circumference and body mass index values based on 10-year absolute type 2 diabetes risk in an Australian Aboriginal community
}

\author{
Odewumi Adegbija, ${ }^{1}$ Wendy E Hoy, ${ }^{2}$ Zhiqiang Wang ${ }^{2}$
}

To cite: Adegbija 0, Hoy WE, Wang Z. Corresponding waist circumference and body mass index values based on 10-year absolute type 2 diabetes risk in an Australian Aboriginal community. BMJ Open Diabetes Research and Care 2015;3:e000127. doi:10.1136/bmjdrc-2015000127

Received 22 June 2015 Revised 13 August 2015 Accepted 19 August 2015

\section{(1) crosshath}

${ }^{1}$ Centre for Chronic Disease, School of Medicine, University of Queensland, Brisbane, Queensland, Australia

${ }^{2}$ Centre for Chronic Disease, School of Medicine, University of Queensland, Brisbane, Queensland, Australia

\section{Correspondence to} Dr Odewumi Adegbija; o.adegbija@uq.edu.au

\section{ABSTRACT}

Objective: There is a lack of waist circumference (WC) thresholds to identify Aboriginal individuals at high risk of type 2 diabetes. We generated genderspecific WC values with equivalent 10-year absolute risk of type 2 diabetes as body mass index (BMI) points in an Australian Aboriginal community to contribute to guidelines needed for establishing WC cut-off points for Aboriginals.

Research design and methods: A cohort of 803 adult participants free from type 2 diabetes in an Aboriginal community was followed up for up to 20 years. We derived WC values with absolute risks equivalent for the development of type 2 diabetes as BMI values $\left(20-35 \mathrm{~kg} / \mathrm{m}^{2}\right)$ using the Weibull accelerated failure-time model.

Results: After a mean follow-up of 15.7 years, 110 participants developed type 2 diabetes. Absolute risk of type 2 diabetes increased as WC increased, ranging from $3.52 \%(W C=77.5 \mathrm{~cm})$ to $14.14 \%(W C=119.9 \mathrm{~cm})$ in males, and $5.04 \%(\mathrm{WC}=79.5 \mathrm{~cm})$ to $24.25 \%$ $(\mathrm{WC}=113.7 \mathrm{~cm})$ in females. In males, $W C$ values with same absolute risks of type 2 diabetes as BMI values were $77.5 \mathrm{~cm}$ for $\mathrm{BMI}=20 \mathrm{~kg} / \mathrm{m}^{2}, 91.5 \mathrm{~cm}$ for $\mathrm{BMI}=25 \mathrm{~kg} / \mathrm{m}^{2}$ (overweight threshold), $105.7 \mathrm{~cm}$ for $\mathrm{BMl}=30 \mathrm{~kg} / \mathrm{m}^{2}$ (obesity threshold) and $119.9 \mathrm{~cm}$ for $\mathrm{BMI}=35 \mathrm{~kg} / \mathrm{m}^{2}$. In females, WC values were $79.5 \mathrm{~cm}$ for $\mathrm{BMl}=20 \mathrm{~kg} / \mathrm{m}^{2}, 90.9 \mathrm{~cm}$ for $\mathrm{BMI}=25 \mathrm{~kg} / \mathrm{m}^{2}$, $102.3 \mathrm{~cm}$ for $\mathrm{BMI}=30 \mathrm{~kg} / \mathrm{m}^{2}$ and $113.7 \mathrm{~cm}$ for $\mathrm{BMI}=35 \mathrm{~kg} / \mathrm{m}^{2}$. Interaction between $W \mathrm{C}$ and gender was not statistically significant $(p=0.53)$.

Conclusions: The absolute risk of type 2 diabetes increased with higher WC measured at baseline screening. Males were not significantly different from females in the association between WC and type 2 diabetes. Our findings are useful contributions for future establishment of WC cut-off points for identifying high-risk individuals in Aboriginal people.

\section{INTRODUCTION}

Central obesity measured by waist circumference (WC) is a known and reported risk factor for type 2 diabetes in the Aboriginal population. ${ }^{1-3}$ Risk thresholds for WC derived from body mass index (BMI) in

\section{Key messages}

- Using the absolute risk method, we derived for overweight defined as body mass index (BMI) of $25 \mathrm{~kg} / \mathrm{m}^{2}$, waist circumference (WC) of $91.5 \mathrm{~cm}$ for males and $90.9 \mathrm{~cm}$ for females; and for obesity (BMI of $30 \mathrm{~kg} / \mathrm{m}^{2}$ ), WC was 105.7 and $102.3 \mathrm{~cm}$ for males and females, respectively.

- There were no significant differences between males and females in the association of WC and type 2 diabetes.

- The generated WC values with similar risk as specific BMI points can contribute to the development of WC cut-off points for Aboriginals in Australia.

predominantly European populations have been proposed for use in Australia. However, these standards might not necessarily be applicable to the Aboriginal population who experience a disproportionately greater burden of type 2 diabetes ${ }^{45}$ and display a body habitus that is different from non-Aboriginals in Australia. ${ }^{6}$ Aboriginals, particularly females, have a tendency for preferential abdominal fat deposition, ${ }^{6} 7$ of which the cause is complex and multifactorial, and to which genetics, lifestyle, inflammation and infections have been suggested to be contributory. ${ }^{8}$ Although the International Diabetes Federation (IDF) has recommended that investigations be performed to determine WC cut-off values for clinical practice in different ethnic regions, ${ }^{9}$ there is no consensus on WC cut-off points to identify individuals at high risk of chronic diseases in Aboriginal Australians.

The conventional sensitivity and specificity approach used by most studies to determine cut-off values has been questioned and the absolute risk approach has been recommended. ${ }^{10}$ Furthermore, WC has been found to be a better predictor of type 2 diabetes than BMI in the Aboriginal population, ${ }^{1} 3$ which provides the basis for conducting this 
study. The present study aimed to estimate the absolute risks of type 2 diabetes prospectively by following up participants free from type 2 diabetes at baseline examination to derive WC values with absolute risks of type 2 diabetes equivalents to BMI points. The estimates generated from this study will contribute to the establishment of WC cut-off points to identify individuals at increased risk of developing type 2 diabetes in the Aboriginal population.

\section{RESEARCH DESIGN AND METHODS}

We conducted a prospective cohort study of adults (aged 18-76 years) using data collected during a community screening program (baseline screening) in an Aboriginal community in the Northern Territory of Australia. The baseline data of eligible participants included age, BMI and WC. ${ }^{11}$ WC was measured in centimeters halfway between the lowest ribs and the iliac crest, while BMI was calculated by participant's weight in kilograms divided by their height in meter-squared $\left(\mathrm{kg} / \mathrm{m}^{2}\right)$. A total of 976 adults participated in the baseline community screening program from 1992 to 1998. Of the 976 adults, 803 had records of age (years), as well as BMI and WC measurements and were free from type 2 diabetes at baseline. They represented over $80 \%$ of the adults in the study population. We followed up the eligible 803 adults on hospitalization records until 31 December 2012 to identify new incident type 2 diabetes cases using the International Classification of Diseases (ICD) codes: 250 (ICD-9) and E11 (ICD-10). Our study outcome was hospital-diagnosed type 2 diabetes before or by 31 December 2012. For participants identified with type 2 diabetes, their follow-up time was calculated from the time of their baseline screening to their first episode of type 2 diabetes according to the hospitalization records. Those who had not developed type 2 diabetes by 31 December 2012 were 'censored'.

Participants volunteered for the baseline screening examinations, and written informed consent was obtained from each participant prior to the data collection. The Ethics Committee of the Menzies School of Health Research and Territory Health Service, and the Aboriginal community approved the original baseline data sets used for this study. The Behavioural and Social Science Ethical Review Committee of the University of Queensland (\#2011001232) gave approval of this study.

\section{Statistical analyses}

Data were analyzed and presented as means with SD and frequencies as appropriate. Interaction between gender and WC was assessed for their association with type 2 diabetes using fractional polynomial regression. The Weibull accelerated failure-time model was used to estimate the absolute type 2 diabetes risk using the formula:

$$
\text { Absolute risk }=1-\exp \left[-\left\{\exp \left(-\beta_{0}-\mathrm{X}_{\mathrm{j}} \beta_{\mathrm{j}}\right) \mathrm{t}_{\mathrm{j}}\right\}^{\mathrm{P}}\right],
$$

where $\beta_{0}$ represented the baseline BMI or WC coefficient, $\beta_{\mathrm{j}}$ was the coefficient for covariates (BMI or WC and age), $X_{j}$ represented the covariates, $t$ is the time and $\mathrm{p}$ the shape parameter.

The gender-specific estimates of equal WC values that corresponded in absolute risks to BMI values from 20 to $35 \mathrm{~kg} / \mathrm{m}^{2}$ for a 10-year risk for type 2 diabetes, at a population average age of 35 years were obtained. All statistical analyses were performed using Stata statistical software V.13.0. ${ }^{12}$ Tests were two-tailed and a $\mathrm{p}$ value of 0.05 was used to indicate statistical significance.

\section{RESULTS}

Our study included 803 participants (419 males and 384 females). The mean age at baseline was 32.1(SD 10.7) years for males and 35.0 (12.9) years for females. In females, the mean values of baseline WC $(89.0 \mathrm{~cm})$ and BMI $\left(24.2 \mathrm{~kg} / \mathrm{m}^{2}\right)$ were higher than in males $\left(\mathrm{WC}=85.9 \mathrm{~cm}\right.$ and $\left.\mathrm{BMI}=23.1 \mathrm{~kg} / \mathrm{m}^{2}\right)$. Participants were followed up for 12633.5 person-years with mean follow-up time of 15.7 years. There were 110 cases of incident type 2 diabetes (38 males and 72 females) during the follow-up period.

Table 1 presents results of the WC values generated from BMI for a 10-year type 2 diabetes absolute risk, at the average age of 35 years. Absolute risk of type 2 diabetes increased with increasing WC values. The interaction between WC and gender showed no statistical significance $(\mathrm{p}=0.53)$. The absolute risk equations used to generate the values on table 1 are presented below:

Table 1 Estimated 10-year gender-specific absolute risks of type 2 diabetes using equivalent WC values corresponding to BMI points at the age of 35 years

\begin{tabular}{|c|c|c|c|c|}
\hline \multirow[b]{2}{*}{ BMI $\left(\mathrm{kg} / \mathrm{m}^{2}\right)$} & \multicolumn{2}{|l|}{ Males } & \multicolumn{2}{|l|}{ Females } \\
\hline & $\overline{W C ~(c m) ~}$ & AR (\%) & $\overline{W C ~(c m) ~}$ & AR (\%) \\
\hline 20 & 77.5 & 3.52 & 79.5 & 5.04 \\
\hline 21 & 80.0 & 3.87 & 81.8 & 5.62 \\
\hline 22 & 83.0 & 4.25 & 84.1 & 6.27 \\
\hline 23 & 85.8 & 4.67 & 86.4 & 6.99 \\
\hline 24 & 88.7 & 5.14 & 88.7 & 7.78 \\
\hline 25 & 91.5 & 5.64 & 90.9 & 8.66 \\
\hline 26 & 94.4 & 6.20 & 93.2 & 9.63 \\
\hline 27 & 97.2 & 6.80 & 95.5 & 10.72 \\
\hline 28 & 100.0 & 7.46 & 97.8 & 11.91 \\
\hline 29 & 102.9 & 8.19 & 100.1 & 13.22 \\
\hline 30 & 105.7 & 8.98 & 102.3 & 14.67 \\
\hline 31 & 108.5 & 9.84 & 104.6 & 16.26 \\
\hline 32 & 111.4 & 10.79 & 106.9 & 18.00 \\
\hline 33 & 114.2 & 11.81 & 109.2 & 19.91 \\
\hline 34 & 117.1 & 12.93 & 111.5 & 21.99 \\
\hline 35 & 119.9 & 14.14 & 113.7 & 24.25 \\
\hline
\end{tabular}

$\mathrm{AR}$, absolute risk; $\mathrm{BMI}$, body mass index; $\mathrm{WC}$, waist circumference. 
For males

$$
\begin{aligned}
\text { Absolute risk }(\mathrm{BMI})= & 1-(\exp [-\{\exp (-8.3367 \\
& -(-0.0855 \times \mathrm{BMI}-0.0392 \times \text { Age })) \\
& \left.\left.\left.\times \mathrm{t}_{\mathrm{j}}\right\}^{1.1281}\right]\right),
\end{aligned}
$$

Absolute risk $(\mathrm{WC})=1-(\exp [-\{\exp (-8.8008$

$$
\begin{aligned}
& -(-0.0300 \times \mathrm{WC}-0.0353 \times \text { Age })) \\
& \left.\left.\left.\times \mathrm{t}_{\mathrm{j}}\right\}^{1.1323}\right]\right) .
\end{aligned}
$$

For females:

$$
\begin{aligned}
\text { Absolute risk }(\mathrm{BMI})= & 1-(\exp [-\{\exp (-6.6145 \\
& -(-0.0837 \times \mathrm{BMI}-0.0122 \times \text { Age })) \\
& \left.\left.\left.\times \mathrm{t}_{\mathrm{j}}\right\}^{1.3388}\right]\right),
\end{aligned}
$$

$$
\begin{aligned}
\text { Absolute risk }(\mathrm{WC})= & 1-(\exp [-\{\exp (-7.6955 \\
& -(-0.0369 \times \mathrm{WC}-0.0066 \times \text { Age })) \\
& \left.\left.\left.\times \mathrm{t}_{\mathrm{j}}\right\}^{1.3307}\right]\right) .
\end{aligned}
$$

In males, WC values with same absolute risks of type 2 diabetes as BMI-specific values ranged from $77.5 \mathrm{~cm}$ for BMI of $20 \mathrm{~kg} / \mathrm{m}^{2}$ (absolute risk=3.52\%) to $119.9 \mathrm{~cm}$ for BMI of $35 \mathrm{~kg} / \mathrm{m}^{2}$ (absolute risk=14.14\%). Derived WC values of 91.5 and $105.7 \mathrm{~cm}$ had similar absolute risks of type 2 diabetes with BMI of 25 (overweight threshold) and $30 \mathrm{~kg} / \mathrm{m}^{2}$ (obesity threshold), respectively. Likewise, for females, WC values ranged from $79.5 \mathrm{~cm}$ for BMI of $20 \mathrm{~kg} / \mathrm{m}^{2}$ (absolute risk $=5.04 \%$ ) to $113.7 \mathrm{~cm}$ for BMI of $35 \mathrm{~kg} / \mathrm{m}^{2} \quad$ (absolute risk=24.25\%). $\quad \mathrm{WC}=90.9$ and $102.3 \mathrm{~cm}$ had equivalent absolute type 2 diabetes risk as BMI of 25 and $30 \mathrm{~kg} / \mathrm{m}^{2}$, respectively.

\section{DISCUSSION}

The major findings in this study were the estimated WC values which were equivalent to BMI values from 20 to $35 \mathrm{~kg} / \mathrm{m}^{2}$ for predicting the absolute risks of type 2 diabetes for Aboriginal people. Also of importance is that the absolute type 2 diabetes risk increased as $\mathrm{WC}$ increased, ranging from $3.52 \%(\mathrm{WC}=77.5 \mathrm{~cm})$ to $14.14 \%$ $(\mathrm{WC}=119.9 \mathrm{~cm})$ in males and $5.04 \%(\mathrm{WC}=79.5 \mathrm{~cm})$ to $24.25 \%(\mathrm{WC}=113.7 \mathrm{~cm})$ in females. WC of 91.5 and $90.9 \mathrm{~cm}$ for males and females, respectively, corresponded with BMI of $25 \mathrm{~kg} / \mathrm{m}^{2}$ (overweight threshold), while WC of $105.7 \mathrm{~cm}$ in males and $102.3 \mathrm{~cm}$ in females corresponded with obesity threshold $\left(\mathrm{BMI}=30 \mathrm{~kg} / \mathrm{m}^{2}\right)$. Although, on average, females had higher WC compared with males (approximately $3.1 \mathrm{~cm}$ mean difference) and the absolute risks tend to be higher in females for each derived WC than in males, the association between WC and type 2 diabetes was not dependent on gender. While there appeared to be widening difference between gender-derived WC at BMI $>30 \mathrm{~kg} / \mathrm{m}^{2}$, with greater increase in males, interactions did not show statistical significance (results not shown). This could potentially be due to the fewer numbers of those with BMI above $30 \mathrm{~kg} / \mathrm{m}^{2}$ and incident type 2 diabetes outcomes at that level.

There is limited evidence of contribution to the development of WC cut-offs for identifying individuals at high risk of chronic disease for Aboriginals in Australia. Although a few studies have shown the link between WC and type 2 diabetes, we are not aware of any study that has determined using either cross-sectional or cohort design what levels of WC increased the risk of type 2 diabetes among Aboriginals. Potential reasons for this lack may be due to the diversity in WC estimate levels existing in Aboriginal communities and the specific statistical technique required to testing this heterogeneity. This study has taken a step in overcoming these two challenges by making some contributions to whatever guidelines will be required in future research to attain this goal. There could be debates on the need for WC thresholds for type 2 diabetes in the Aboriginal population as high WC appears to be a phenomenon with reported tendency for central obesity even at younger ages. ${ }^{13}$ However, the evidence linking WC with type 2 diabetes is strong and consistent in the Aboriginal population. $^{1-3}$ Furthermore, WC has been found to be a better predictor of type 2 diabetes compared with BMI, waist-to-hip ratio, as well as weight and hip circumference in the Aboriginal population. ${ }^{3}$ There have been reports evidenced by improved or completely normalized metabolic abnormalities of type 2 diabetes among Aboriginals after a short reversion to traditional huntergatherer lifestyle which entailed high physical activity and low-fat diets resulting in weight loss. ${ }^{14}$ Although preventing excessive weight gain among Aboriginals is a complex process due to the strong link between poverty and obesity, ${ }^{15}$ the hypothesis that weight loss results in reduced $\mathrm{WC}$, and also, controlling risk of complications that have been associated with risk of type 2 diabetes are supported by trial studies outside Australia. ${ }^{16}{ }^{17}$ Therefore, operational definition of central obesity is important and necessary for health promotion in this population. As WC is easy to measure with no required calculations, unlike BMI, and has been found to have stronger association with type 2 diabetes than BMI and other anthropometric indices, ${ }^{1}{ }^{3}$ establishment of threshold WC values in the Aboriginal population will be beneficial for individuals and healthcare workers to help reduce the prevalence of type 2 diabetes among this Australian group.

As the Aboriginal Australian population is heterogeneous in their WC levels, varying from one community to another, future studies using the absolute risk approach should be assessed prospectively in other Aboriginal communities to examine the similarities or differences between males and females in the association between WC and type 2 diabetes. Furthermore, the absolute risk method used in this study would benefit the 
diverse Aboriginal population by demonstrating the applicability of our findings in WC-homogeneous communities.

The use of prospective study design with a long-term follow-up period is the main strength of this study. However, the findings from an Aboriginal community may not be generalizable to all communities due to the heterogeneity in WC levels among different Aboriginal groups. Replicating this study using the absolute risk method in other Aboriginal communities or larger Aboriginal groups will further confirm the generalizability of our findings.

In summary, absolute risks of type 2 diabetes increased as WC increased. For overweight defined as BMI of $25 \mathrm{~kg} / \mathrm{m}^{2}$, WC was $91.5 \mathrm{~cm}$ for males and $90.9 \mathrm{~cm}$ for females, while for obesity, BMI of $30 \mathrm{~kg} / \mathrm{m}^{2}$, $\mathrm{WC}=105.7$ and $102.3 \mathrm{~cm}$ for males and females, respectively. Males and females did not differ remarkably in the relationship between WC and type 2 diabetes. This similarity was also reflected in the derived WC estimates with equal absolute risks of type 2 diabetes as corresponding overweight and obesity BMI values. The findings of this study will be useful for health professionals and public health workers when evaluating the risk of elevated WC in association with type 2 diabetes. Also, our results are important and useful for future research in the development of WC cut-off points in the Aboriginal population.

Acknowledgements The authors thank the Aboriginal people who participated in this study. This project was supported by National Health and Medical Research Council of Australia (APP1025350). The baseline screening was supported by NHMRC grant (320860). The authors appreciate Dr Wendy E Hoy's NHMRC Australia Research Fellowship (\#511081).

Contributors All authors contributed to the study design. WEH and ZW were involved in acquisition of the original data. $\mathrm{OA}$ performed the literature searches, data analysis, and interpretation of data and drafting of the manuscript, and critical revision of the manuscript. ZW worked closely and supervised $\mathrm{OA}$ in the data analyses. All authors revised and approved the final manuscript. WEH is the guarantor and therefore takes responsibility for the integrity for this research work, the study design and access to data.

Funding National Health and Medical Research Council.

Competing interests None declared.

Ethics approval The Behavioural and Social Science Ethical Review Committee of the University of Queensland.

Provenance and peer review Not commissioned; externally peer reviewed.
Data sharing statement The data used for this study can be made available on request by the corresponding author of this study.

Open Access This is an Open Access article distributed in accordance with the Creative Commons Attribution Non Commercial (CC BY-NC 4.0) license, which permits others to distribute, remix, adapt, build upon this work noncommercially, and license their derivative works on different terms, provided the original work is properly cited and the use is non-commercial. See: http:// creativecommons.org/licenses/by-nc/4.0/

\section{REFERENCES}

1. Wang Z, Hoy WE. Body size measurements as predictors of type 2 diabetes in Aboriginal people. Int J Obes Relat Metab Disord 2004:28:1580-4.

2. McDermott RA, Li M, Campbell SK. Incidence of type 2 diabetes in two Indigenous Australian populations: a 6-year follow-up study. Med J Aust 2010;192:562-5.

3. Adegbija O, Hoy W, Wang Z. Predicting absolute risk of type 2 diabetes using age and waist circumference values in an aboriginal Australian community. PLOS ONE 2015;10:1-10.

4. Diabetes Australia. Diabetes: the silent pandemic and its impact on Australia. 2012:1-27. http://wwwdiabetesaustraliacomau/Documents/ DA/What $\% 27$ s\%20New/120314\%20Diabetes\%20management\% 20booklet\%20FINALpdf

5. Australian Institute of Health and Welfare. Diabetes: Population of interest. 2015. http://wwwaihwgovau/diabetes/populations-of-interest/

6. Kondalsamy-Chennakesavan S, Hoy WE, Wang Z, et al. Anthropometric measurements of Australian Aboriginal adults living in remote areas: comparison with nationally representative findings. Am J Hum Biol 2008;20:317-24.

7. Adegbija OO, Wang Z. Gender variations in waist circumference levels between Aboriginal and non-Aboriginal Australian populations: a systematic review. Obes Res Clin Pract 2014;8:e513-24.

8. Hoy WE, Kondalsamy-Chennakesavan S, McDonald S, et al. Renal disease, the metabolic syndrome, and cardiovascular disease. Ethn Dis 2006;16(2 Suppl 2):S2-46-51.

9. Alberti KG, Zimmet P, Shaw J. Metabolic syndrome-a new worldwide definition. A Consensus Statement from the International Diabetes Federation. Diabet Med 2006;23:469-80.

10. Wang Z, Ma J, Si D. Optimal cut-off values and population means of waist circumference in different populations. Nutr Res Rev 2010;23:191-9.

11. Wang Z, Hoy WE. Waist circumference, body mass index, hip circumference and waist-to-hip ratio as predictors of cardiovascular disease in Aboriginal people. Eur J Clin Nutr 2004;58:888-93.

12. StataCorp. Stata Statistical Software: Release 13. College Station, TX: StataCorp LP, 2013.

13. Sellers EA, Singh GR, Sayers SM. Large waist but low body mass index: the metabolic syndrome in Australian Aboriginal children. J Pediatr 2008:153:222-7.

14. O'Dea K. Marked improvement in carbohydrate and lipid metabolism in diabetic Australian aborigines after temporary reversion to traditional lifestyle. Diabetes 1984;33:596-603.

15. O'Dea K, Rowley KG, Brown A. Diabetes in Indigenous Australians: possible ways forward. Med J Aust 2007;186:494-5.

16. Tate DF, Jackvony EH, Wing RR. Effects of Internet behavioral counseling on weight loss in adults at risk for type 2 diabetes: a randomized trial. JAMA 2003:289:1833-6.

17. Han TS, Richmond P, Avenell A, et al. Waist circumference reduction and cardiovascular benefits during weight loss in women. Int J Obes Relat Metab Disord 1997;21:127-34. 